\title{
THE USE OF ADJUVANT NUTRITION TO PRESERVE AND INCREASE LEAN BODY MASS IN AIDS PATIENTS WITH MUSCLE WASTING.
}

CRADA No. BNL-C-97-09 Between BNL and Metabolic Technologies, Inc.

RECEIVED

JAN 032080

The studies conducted under this CRADA were aimed at determining if nutritional supplementation with $\mathrm{HM}$, in combination with glutamine and arginine can ameliorate, the AIDS-associated wasting syndrome and in turn improve the clinical course of the disease.

\section{Final Abstract}

Loss of lean body mass (LBM) and a decline in body cell mass are the earliest manifestations of the AIDS-associated wasting syndrome; these losses occur prior to any changes in total body weight and are associated with net preservation of total body fat. AIDS-associated wasting syndrome leads to increased morbidity and mortality. Attempts to prevent wasting have included pharmacological, hormonal and nutritional interventions; most, at prohibitive cost to the patients, have had limited and transient results, and often were associated with deleterious side effects. Previously, we showed in healthy volunteers that the combination of daily supplementation ( 3.0 grams/day) with the leucine metabolite, $\beta$-hydroxy $\beta$-methyl butyrate (HMB), and resistance-exercise, curtailed muscle proteolysis and increased fat free mass (FFM). Based on these observations, we hypothesized that the AIDS-associated muscle wasting can also be overridden by appropriate tissue-specific nutrition. AIDS patients $(n=13$; age $43 \pm 7$ y; viral load range 50 to 29,000 copies $/ \mathrm{ml}$ ) were recruited into the study. They were given daily supplements of a newly designed nutrient mixture consisting of HMB (3.0 grams/day), arginine and glutamine (14 grams/day, each) in two divided doses (Juven ${ }^{\mathrm{TM}}$, Metabolic Technologies, Inc, Ames, IA) for six weeks. In addition, 13 patients successfully completed the 12 week protocol and Juven ${ }^{\mathrm{TM}}$ supplementation resulted in an increased total body weight $(1.2 \pm 0.4 \mathrm{~kg} ; \mathrm{p}=0.03)$ which was associated with a significant increase in FFM $(0.8 \pm 0.3 \mathrm{~kg}, \mathrm{p}<0.05)$. Juven ${ }^{\mathrm{TM}}$ also increased thigh circumference $(0.6 \pm 0.3 \mathrm{~cm})$ and percent $(6 \%)$ muscle mass (using regional BIA, both $\mathrm{p}<0.05$ ).

These findings suggest that daily supplementation with Juven ${ }^{\mathrm{TM}}$, consisting of HMB, arginine and glutamine is an effective, natural, cost efficient alternative for preserving lean body mass in AIDS patients. Juven ${ }^{\mathrm{TM}}$ supplementation increased total body weight $(1.2 \pm 0.4 \mathrm{~kg} ; \mathrm{p}=0.03)$ which was associated with a significant increase in FFM $(0.8 \pm 0.3 \mathrm{~kg}, \mathrm{p}<0.05)$ as measured by bioelectrical impedance analysis. Juven ${ }^{\mathrm{TM}}$ also increased thigh circumference $(0.6 \pm 0.3 \mathrm{~cm})$ and percent $(6 \%)$ muscle mass (using regional BIA, both $\mathrm{p}<0.05)$. However, it did not change resting energy expenditure, determined by indirect calorimetry, but increased RQ (respiratory quotient. from $0.84 \pm 0.05$ to $0.89 \pm 0.04, \mathrm{p}<0.05$ ). These findings suggest that daily supplementation with Juven ${ }^{\mathrm{TM}}$, consisting of $\mathrm{HMB}$, arginine and glutamine is an effective, natural, cost efficient alternative for preserving lean body mass in AIDS patients.

\section{Significant accomplishments:}

The integration of Industry, North Shore University Hospital and Brookhaven National laboratories in conducting this clinical study is one of the main asramnlishmente of the nrecent 
CRADA. Several factors made the successful completion of the study a significant accomplishment including geographic location of the hospital and of a greater pool of HIV infected patients willing to participate in the study (closer to New York City), need for presence of the volunteers at more than one place on a given day (physical and medical evaluations at North Shore University Hospital as well as body composition measures at both BNL and NSUH). In addition, the longitudinal nature of the study required constant and dedicated involvement of a Nurse Practitioner throughout the duration of the study. Overall, however, we consider the coordinated effort from the three main components of the project (Industry, NSUH and BNL) to have been a success. Our results suggest that daily supplementation with Juven ${ }^{\mathrm{TM}}$, consisting of $\mathrm{HMB}$, arginine and glutamine is an effective, natural, cost efficient alternative for preserving lean body mass in AIDS patients.

\section{Significant problems:}

Problems encountered with the completion of this project pertained to both patient recruitment and compliance as well as to the operation of the facilities. Only 17 patients were recruited over a two year period with 12 completing the 12 week protocol to date. During a $3+$ month period, it was not possible to conduct the studies at BNL due to safety issues relating to the administration of tritriated water to determine total body water. This was immediately followed by an additional period in which the facilities were not operational due to electrical problems. This posed a problem due to the longitudinal nature of the studies in which no new subjects could be recruited during the time period when the facility was not operational.

The recruitment of individuals with HIV/AIDS into the study was difficult due to the multiple problems associated with the disease. Thus, entry of the individual into the study required previous recommendation from the Infectious disease treating physician. In addition, once in the study, some patients $(n=5)$ had to be excluded due to several reasons including noncompliance with the appointments, unwillingness to perform urine collections, time constraints and in one instance alterations in hepatic enzyme function tests.

Industry benefits realized: The overall objective of this research to MTI was to test the efficacy of a newly developed nutrient mixture aimed to revert the wasting that occurs in patients with AIDS. It was foreseen that these studies would accelerate the commercialization of this nutrient mixture as an adjuvant nutritional product ( Juven ${ }^{\mathrm{TM}}$ ) to the AIDS population at large. Data generated from these study were intended to reinforce the body composition data generated at another institution in the New York City area. Using the "state of the art" body composition analysis (TBK and IVNA) available at BNL we hoped to confirm that the weight gained with Juven $^{\mathrm{TM}}$ was muscle tissue. It would be difficult to refute these data in the scientific community. However, the last objective was not realized under this CRADA. Incomplete and insufficient data collected made it impossible to reach any statistical conclusions on the TBK or IVNA results. However, body composition data collected at North Shore University Hospital did demonstrate an increase in weight $(1.2 \mathrm{~kg})$ and FFM $(0.8 \mathrm{~kg})$ in 6 weeks with Juven supplementation. These data confirm the findings previously reported. Since the initiation of the CRADA the product, Juven ${ }^{\mathrm{TM}}$, was brought to the U.S. market and has performed quite well.

Laboratory benefits realized: This program used a unique facility of BNL for an advanced clinical trial. The IVNA Facility was developed by the funding from the If o nonartment of 
Energy (DOE) in the 1960s and 1970s. It was then upgraded with NIH funding in mid 1980s and early 1990s. The Facility's Whole Body Counter, with two other similar facilities worldwide, are the largest in its kind. However, the most significant aspect of the facility which makes is unique is that it combines four methods, three of IVNA and one tritiated water dilution measurement, to provide a complete compartmental tissue analysis to provide total body contents of fat, lean mass, bone, cell mass, and intracellular and extracellular water. This program used the unique capabilities of the BNL facility to the fullest.

\section{Recommended follow-on work:}

Upon completion of analysis of all parameters and tabulation of results, it is possible that the number of subjects enrolled in the study was not sufficient to result in a demonstrable difference in body composition as a result of the nutritional supplementation. However, if a trend is observed, then it would be important to follow up this study by increasing the enrollment and thus providing with a more reliable sample to determine the reproducibility of the changes in body composition across the different approaches utilized (BOD-POD vs IVNA).

Potential benefits from pursuing follow-on work: Follow-on work should concentrate on TBK and IVNA measurement with comparison to more commonly used methods (BIA and Bod Pod ${ }^{\mathrm{TM}}$ ). Body composition data obtained from TBK and IVNA methods are needed. 


\section{DISCLAIMER}

This report was prepared as an account of work sponsored by an agency of the United States Government. Neither the United States Government nor any agency thereof, nor any of their employees, make any warranty, express or implied, or assumes any legal liability or responsibility for the accuracy, completeness, or usefulness of any information, apparatus, product, or process disclosed, or represents that its use would not infringe privately owned rights. Reference herein to any specific commercial product, process, or service by trade name, trademark, manufacturer, or otherwise does not necessarily constitute or imply its endorsement, recommendation, or favoring by the United States Government or any agency thereof. The views and opinions of authors expressed herein do not necessarily state or reflect those of the United States Government or any agency thereof. 


\section{DISCLAIMER}

Portions of this document may be illegible in electronic image products. Images are produced from the best available original document. 